\title{
KEANEKARAGAMAN DAN KELIMPAHAN LALAT BUAH (DIPTERA: TEPHRITIDAE) PADA BEBERAPA SISTEM PENGGUNAAN LAHAN DI BUKIT RIGIS, SUMBERJAYA, LAMPUNG BARAT
}

\author{
Nismah $^{1}$ dan F.X. Susilo ${ }^{2}$
}

\begin{abstract}
Diversity and abundance of fruit flies (Diptera: Tephtritidae) in a range of land use systems in Sumberjaya, West Lampung. Fruit fly inventory from seven land use systems in Sumberjaya area, West Lampung, using fruit incubation and lure trap methods resulted in four species of fruit flies, i.e. Bactrocera (Bactrocera) dorsalis, B. (B.) umbrosa, B. (Zeugodacus) cucurbitae, dan B. (Afrodacus) furvus. B. dorsalis was the most common fruit flies in the area while the least found was B. (A) furvus. The abundance of fruit flies was positively correlated with the weight of cempedak fruit (Artocarpus polyphema, Moraceae) and of the watery roseapple fruit (Syzygium aqueum, Myrtaceae).
\end{abstract}

Key words : fruit flies, land use, diversity

\section{PENDAHULUAN}

Kecamatan Sumberjaya secara administratif termasuk wilayah Kabupaten Lampung Barat, dan secara geografis terletak pada $4^{\circ} 45^{\prime}-5^{\circ} 15^{\prime}$ LS dan $104^{\circ} 15^{\prime}-104^{\circ} 45^{\prime} \mathrm{BT}$ dengan ketinggian $700-1.700$ $\mathrm{m}$ dpl. Batas wilayahnya berupa pergunungan yang bersambungan. Pada bagian tengah wilayah kecamatan ini terdapat hutan lindung Bukit Rigis dengan luas wilayah 35.446 ha (Agus et al., 2002). Dari luasan tersebut lebih kurang $28 \%( \pm 2.400 \mathrm{ha}) \mathrm{di}$ antaranya telah beralih fungsi dari hutan lindung menjadi lahan pertanian. (Dinas Kehutanan Lampung Barat, 1992; Pemcam Sumberjaya, 2004). Evizal et al. (2004), mengelompokkan perubahan alih fungsi lahan yang terjadi di kawasan Bukit Rigis ke dalam tujuh sistem penggunaan lahan (SPL), yaitu hutan alami (HA), hutan tebang (HT), kebun kopi polikultur (KKP), kebun kopi monokultur (KKM), lahan tanaman pangan (LTP), lahan tanaman hortikultura (LTH), dan padang alang-alang (PAA). Alih guna lahan dari hutan alami menjadi berbagai tipe penggunaan lahan pertanian mengubah vegetasi penutup lahan, baik komposisi maupun strukturnya sehingga diperkirakan berdampak kepada keberadaan dan kemelimpahan faunanya. Habitat hutan alami yang telah dibuka biasanya digunakan untuk budidaya tanaman hortikultura (buah-buahan dan sayuran) dan agroforestri (Evizal et al., 2004). Keberadaan tanaman hortikultura, terutama buah-buahan sangat erat kaitannya dengan keberadaan dan kemelimpahan lalat buah (Kardinan, 2007).

Tanaman hortikultura merupakan salah satu andalan masyarakat sebagai sumber pangan dan sumber pendapatan, bahkan bisa dijadikan sebagai sumber devisa melaui ekspor sayur dan buah-buahan. Namun usahatani tanaman hortikultura ini tidak terlepas dari gangguan serangga hama, baik pada masa pertumbuhan maupun pada pasca panen (Evizal et al., 2004; Papulung \& Agus, 2006; Putra et al., 2006; Kardinan, 2007; Vedder, 2007).

Salah satu kelompok serangga yang merupakan hama penting bagi tanaman holtikultura adalah lalat buah. Serangan lalat buah menyebabkan kerugian baik secara kuantitas maupun kualitas (Putra et al., 2006; Dinas Informasi dan Komunikasi, 2007; Hartanto, 2007; Kardinan, 2007; Vedder, 2007; Balittro, 2008). Luas serangan lalat buah di Indonesia mencapai 4.790 ha dengan kerugian mencapai 21,99 miliar rupiah (Balittro, 2008). Akhir-akhir ini dilaporkan, kerugian yang diderita petani belimbing di Depok, misalnya, mencapai 9 juta rupiah untuk setiap ha tanaman belimbing yang terserang lalat buah (Republika, 2008). Besarnya kerugian akibat kerusakan yang ditimbulkan lalat buah di tempat lain (Australia) diperkirakan mencapai 100 juta dolar AS per tahun apabila lalat buah tersebut tidak dikendalikan (FAO, 1986). Di California AS, kehilangan hasil mencapai 910 juta dolar AS akibat serangan delapan jenis lalat buah (Dowell \& Wange, 1986).

\footnotetext{
${ }^{1}$ Jurusan Biologi, Fakultas Matematika dan Ilmu Pengetahuan Alam, Universitas Lampung

2 Jurusan Proteksi Tanaman, Fakultas Pertanian, Universitas Lampung Jl. Prof. Soemantri Brodjonegoro No. 1 Bandar Lampung 35145
} 
Lalat buah tergolong Ordo Diptera, Famili Tephrinidae, Subfamili Dacinae, Tribus Dacini. Di seluruh dunia terdapat lebih kurang 4.000 spesies Tephritidae dari 500 genus, 160 genus di antaranya ditemukan di Asia (Siwi et al., 2006). Tribus Dacini sendiri terdiri atas tiga genus, yaitu Bactrocera, Dacus, dan Monacrostichus (White \& Marlene,1992). Hardy (1977) mengelompokkan genus Bactrocera menjadi 3 subgenus, yaitu: Bactrocera (Bactrocera), Bactrocera (Strumeta), dan Bactroceca (Zeugodacus).

Tidak semua spesies lalat buah merugikan, hanya kira-kira $10 \%$ yang merupakan hama. Di IndoPasifik dilaporkan ada 800 spesies lalat buah, tetapi hanya 60 spesies yang merupakan hama penting. Di Indonesia bagian barat terdapat 90 spesies lalat buah lokal (indigenous), tetapi hanya 8 spesies yang termasuk hama penting, yaitu; B. (B.) albistrigata (deMeijere), B. (B.) carambolae (Drew \& Hancock), $B$.(B.) papayae (Drew \& Hancock), B. (B.) umbrosa (Fabricius), B. (B.) dorsalis (Handel), B. (Z.) cucurbitae (Coquillett), B. (Z.) tau (Walker), dan Dacus (Callantra) longicornis (Wiedemann) (White \& Marlene,1992; Orr, 2002; Siwi et al., 2006). Bactrocera adalah genus asli tropika yang secara ekonomis merupakan lalat buah penting yang berasosiasi dengan berbagai buah-buahan tropika. Salah satu spesiesnya yang dapat menyebabkan kerusakan parah pada tanaman hortikultura di Asia (terutama Asia Tenggara) ialah B. dorsalis (Hendel). Spesies ini juga merupakan hama penting di Indonesia bagian barat (Drew \& Hancock, 1994; Siwi et al., 2006).

Akibat dibukanya pasar bebas, perdagangan buah-buahan pada saat ini sudah mendunia, akibatnya lalat buah dari suatu negara dapat menyebar ke berbagai negara lain. Beberapa spesies telah menjadi hama penting di daerah yang jauh dari daerah asalnya (hama eksotik), misalnya Dacus spp. Dacus merupakan genus asli Afrika, namun sekarang telah tersebar di Indonesia. Selain Dacus spp. ada 13 spesies lalat buah yang berpotensi masuk ke Indonesia, antara lain Anastrepha ludens, B. philippinensis, B. tryoni (lalat buah Queensland), Ceratitis capitata (lalat buah Mediterania), Monacrostichus citricola, dan Rhagoleletis completa. Kesemua spesies ini termasuk dalam daftar hama karantina yang sangat berbahaya (Siwi et al., 2006).
Sampai saat ini informasi mengenai keberadaan lalat buah di kawasan Bukit Rigis Kecamatan Sumberjaya, Lampung Barat, belum diketahui. Oleh karena itu penelitian ini ditujukan untuk menginventarisasi keanekaragaman spesies dan kelimpahan lalat buah yang ditemukan di kawasan tersebut. Informasi mengenai keanekaragaman spesies lalat buah ini dapat digunakan sebagai data dasar untuk mengantisipasi ancaman hama ini dan mempersiapkan upaya-upaya pengelolaannya.

\section{METODE PENELITIAN}

Penelitian ini dilakukan di Bukit Rigis, Dusun Bodong Jaya, Desa Sukajaya, Kecamatan Sumberjaya, Lampung Barat. Pengambilan sampel dilakukan pada bulan Januari - Februari 2005 di kawasan Bukit Rigis seluas kira-kira $1,44 \mathrm{~km}^{2}\left(5^{\circ} 01^{\prime} \mathrm{LS}-5^{\circ} 03^{\prime} \mathrm{LS}\right.$ dan $104^{\circ} 26^{\prime} \mathrm{BT}-104^{\circ} 27^{\prime} \mathrm{BT}$ ) pada tujuh SPL (hutan alami (HA), hutan tebang (HT), kebun kopi polikultur (KKP), kebun kopi monokultur (KKM), lahan tanaman pangan (LTP), lahan tanaman hortikultura (LTH), dan padang alang-alang (PAA)). Penentuan titik sampling dilakukan dengan metode grid bertingkat (stratified grid design) dengan jarak antartitik grid $200 \mathrm{~m}$. Penentuan jumlah, lokasi atau sebaran titik sampling didasarkan kepada kemudahan akses, jumlah dan sebaran titik pada setiap SPL, serta luas hamparan per titik sampling. Pada setiap SPL diambil masing-masing 5 titik sampling yang berbeda, sehingga keseluruhan titik sampling berjumlah 35 titik. Pengumpulan sampel lalat buah pada masingmasing titik sampling dilakukan dengan dua cara, yaitu inkubasi buah dan pemasangan perangkap.

Inkubasi buah dilakukan dengan cara mengumpulkan buah-buahan yang jatuh atau rontok dari pohon-pohon buah yang terdapat di dalam plot berukuran $100 \times 100 \mathrm{~m}$ yang ditentukan pada setiap titik sampling. Buah yang didapatkan dimasukkan ke dalam kantong plastik, diberi label, kemudian dibawa ke laboratorium untuk diinkubasi dengan metode yang digunakan Asrida et al. (2001) dan Swibawa et al. (2003). Lalat buah yang muncul dari buah terinkubasi dikoleksi dalam vial-vial beralkohol $70 \%$ kemudian diidentifikasi di bawah mikroskop stereo binokuler dengan Drew et al. (1982), Drew \& Hancock (1994), dan Siwi et al. (2006).

Perangkap yang dipasang terdiri atas dua tipe perangkap (modifikasi Drew et al., 1982). Perangkap I 
dibuat dengan memotong sepertiga bagian ujung depan botol air mineral berukuran $1.500 \mathrm{ml}$ dan bagian tersebut dipasang kembali secara terbalik seperti corong. Ke dalam botol ini dimasukan kapas yang telah diberi dua tetes zat pemikat metil eugenol (cue lure). Perangkap II disiapkan dengan cara membuat empat lubang pada sisi botol air mineral berukuran $1.500 \mathrm{ml}$ sebagai pintu masuk lalat buah. Kemudian ke dalam botol ini dimasukkan zat pemikat (food lure) berupa campuran juice buah markisa matang $(10 \%)$ dan larutan gula pasir (10\%) dengan volume $250 \mathrm{ml}$ per perangkap. Kedua jenis perangkap yang telah disiapkan tersebut, ditempatkan pada masing-masing titik pengambilan sampel. Pengumpulan sampel lalat buah dari perangkap dilakukan setiap minggu, selama 5 minggu. Lalat buah yang terkumpul diawetkan di dalam vial-vial beralkohol $70 \%$ dan diidentifikasi seperti cara pertama.

Peubah-peubah yang diamati pada penelitian ini adalah keanekaragaman jenis, kelimpahan $(\mathrm{K})$, kelimpahan relatif (KR), dan indeks dominansi Berger-Parker (d) pada masing-masing SPL. Analisis korelasi dengan uji $t$ pada taraf 0,05 dilakukan untuk mengetahui hubungan antara berat buah terinkubasi dan jumlah lalat buah yang muncul dari buah terinkubasi tersebut.

\section{HASIL DAN PEMBAHASAN}

Dari hasil identifikasi lalat buah yang terkoleksi dari tujuh SPL di Bukit Rigis, Kecamatan Sumberjaya Lampung Barat ditemukan empat spesies lalat buah, yaitu Bactrocera (Bactrocera) dorsalis (Hendel), B. (B.) umbrosa Fabricius, B. (Zeugodacus) cucurbitae (Coquillet), dan B. (Afrodacus) furvus (May). Jumlah dan persentase dari masing-masing spesies yang ditemukan bervariasi sesuai dengan cara penangkapannya (Tabel 1). B. (B.) dorsalis merupakan spesies lalat buah yang paling banyak di temukan di Bukit Rigis, yaitu 82,6\% dari total temuan, selanjutnya diikuti oleh B. (B.) umbrosa $(14,2 \%)$. Ada pun yang paling sedikit ditemukan (hanya 1 ekor jantan) adalah B. (A.) furvus, yang terperangkap pada zat pemikat juice buah markisa matang (food lure). Banyaknya B. (B.) dorsalis dan B. (B.) umbrosa pada lokasi pengambilan sampel merupakan petunjuk bahwa kedua spesies lalat buah ini tertarik kepada zat pemikat yang berupa food lure (buah dan juice buah markisa matang) dan cue lure (metil eugenol), sehingga ditemukan pada setiap cara pengumpulan sampel. Dua spesies yang lain (B. (Z.) cucurbitae dan B. (A.) furvus hanya tertarik pada food lure (Drew et al., 1982; Drew \& Hancock, 1994; Siwi et al., 2006). Cue lure memerangkap lebih banyak lalat buah dibandingkan dengan food lure (70,6\% versus 28,4\%) (Tabel 1). Hal ini nampaknya mengindikasikan bahwa cue lure merupakan zat pemikat yang lebih kuat dibandingkan food lure. Menurut Drew et al. (1982), kemampuan cue lure dalam memikat lalat buah mempunyai radius yang lebih luas dibandingkan food lure. Metil eugenol, misalnya, mampu memikat lalat buah dalam radius $800 \mathrm{~m}$, sedangkan food lure hanya dalam radius 20 $\mathrm{m}$.

Spesies B. (B.) dorsalis merupakan lalat buah yang mendominasi SPL, dengan indeks dominansinya antara $0,76-1,00$, yang berarti kawasan lahan ini didominasi oleh spesies tersebut. Spesies ini ditemukan pada ketujuh SPL dengan indeks

Tabel 1. Keanekaragaman spesies, jumlah dan persentase lalat buah pada cara pengumpulan sampel yang berbeda

\begin{tabular}{|c|c|c|c|c|c|}
\hline \multirow[b]{2}{*}{ No } & \multirow[b]{2}{*}{ Spesies lalat buah } & \multirow[b]{2}{*}{$\begin{array}{l}\text { Buah rontok } \\
\text { (food lure) }\end{array}$} & \multicolumn{2}{|c|}{ Perangkap } & \multirow{2}{*}{$\begin{array}{c}\% \\
\text { Jenis } \\
\text { lalat } \\
\text { buah }\end{array}$} \\
\hline & & & $\begin{array}{l}\text { Juice buah } \\
\text { Markisa } \\
\text { (food lure) }\end{array}$ & $\begin{array}{l}\text { Metil eugenol } \\
\text { (cue lure) }\end{array}$ & \\
\hline 1. & B. (Bactrocera) dorsalis & $135\left(Q+\phi^{1}\right)$ & $30^{\pi}$ & $4740^{1}$ & 82,6 \\
\hline 2. & B. (B.) umbrosa & $56\left(q+O^{\pi}\right)$ & $20^{\pi}$ & $490^{\pi}$ & 14,2 \\
\hline 3. & B. (Zeugodacus) cucurbitae & $18(q+\overbrace{}^{\pi})$ & $3{ }^{\pi}$ & 0 & 2,8 \\
\hline 4. & B. (Afrodacus) furvus & 0 & $1 \hat{0}$ & 0 & 0.1 \\
\hline & Jumlah (\%) & $209(28,2)$ & $9(1,2)$ & $523(70,6)$ & 100 \\
\hline
\end{tabular}


Tabel 2. Jumlah, kelimpahan, indeks dominansi, dan kelimpahan relatif, masing-masing spesies lalat buah yang ditemukan pada tujuh SPL

\begin{tabular}{|c|c|c|c|c|c|c|c|c|c|c|c|}
\hline \multirow{3}{*}{ No } & \multirow{3}{*}{$\begin{array}{l}\text { Kode } \\
\text { SPL }\end{array}$} & \multicolumn{8}{|c|}{ Spesies lalat buah } & \multirow{3}{*}{$\Sigma \mathrm{N}(\%)$} & \multirow{3}{*}{$\mathrm{d}$} \\
\hline & & \multicolumn{2}{|c|}{ B. dorsalis } & \multicolumn{2}{|c|}{ B. umbrosa } & \multicolumn{2}{|c|}{ B. cucurbitae } & \multicolumn{2}{|c|}{ B. furvus } & & \\
\hline & & $\mathrm{N}$ & $\mathrm{K}$ & $\mathrm{N}$ & $\mathrm{K}$ & $\mathrm{N}$ & $\mathrm{K}$ & $\mathrm{N}$ & $\mathrm{K}$ & & \\
\hline 1 & HT & 20 & 100,0 & 0 & 0 & 0 & 0 & 0 & 0 & $20(2,7)$ & 1,00 \\
\hline 2 & HA & 18 & 100,0 & 0 & 0 & 0 & 0 & 0 & 0 & $18(2,4)$ & 1,00 \\
\hline 3 & KKP & 188 & 81,4 & 39 & 16,9 & 3 & 1,3 & 1 & 0,4 & $231(31,2)$ & 0,81 \\
\hline 4 & KKM & 80 & 85,1 & 14 & 14,9 & 0 & 0 & 0 & 0 & $94(12,7)$ & 0,85 \\
\hline 5 & LTP & 56 & 83,6 & 4 & 6,0 & 7 & 10,4 & 0 & 0 & $67(9,1)$ & 0,84 \\
\hline 6 & LTH & 126 & 76,4 & 26 & 15,7 & 11 & 6,7 & 0 & 0 & $165(22,3)$ & 0,76 \\
\hline \multirow[t]{2}{*}{7} & PAA & 131 & 90,3 & 14 & 9,7 & 0 & 0 & 0 & 0 & $145(19,6)$ & 0,90 \\
\hline & KR & \multicolumn{2}{|c|}{83,6} & \multicolumn{2}{|c|}{13,1} & \multicolumn{2}{|c|}{2,8} & \multicolumn{2}{|c|}{0,2} & $740(100)$ & \\
\hline
\end{tabular}

Keterangan : $\mathrm{HA}=$ hutan alami, $\mathrm{HT}=$ hutan tebang, $\mathrm{KKP}=$ kebun kopi polikultur, $\mathrm{KKM}=$ kebun kopi monokultur, LTP = lahan tanaman pangan, LTH = lahan tanaman hortikultura, PAA = padang alang-alang, $\mathrm{N}=$ jumlah (ekor), $\mathrm{K}=$ kelimpahan (\%), $\mathrm{d}=$ indeks dominansi Berger-Parker $(\mathrm{Nmax} / \mathrm{N})$

Tabel 3. Jumlah dan persentase buah terserang serta jenis dan jumlah lalat buah yang muncul setelah buah diinkubasi

\begin{tabular}{|c|c|c|c|c|c|c|c|c|c|}
\hline \multirow{2}{*}{ No } & \multirow{2}{*}{ Jenis buah/SPL } & \multicolumn{6}{|c|}{ Jumlah buah dan \% terserang } & \multirow{2}{*}{$\begin{array}{l}\text { Spesies } \\
\text { lalat buah }\end{array}$} & \multirow{2}{*}{$\begin{array}{c}\Sigma \\
\text { (ekor) }\end{array}$} \\
\hline & & KKP & KKM & LTP & LTH & PAA & $\%$ & & \\
\hline 1 & Belimbing (Averoa carambola) & 15 & 0 & 0 & 0 & 0 & 60,0 & B. dorsalis & 43 \\
\hline 2 & $\begin{array}{l}\text { Cabe merah (Capsicum } \\
\text { annuum) }\end{array}$ & 0 & 0 & 0 & 90 & 0 & 55,6 & B. dorsalis & 29 \\
\hline 3 & $\begin{array}{l}\text { Cabe rawit } \\
\text { (C. frutescens) }\end{array}$ & 15 & 0 & 15 & 100 & 0 & 46,2 & B. dorsalis & 17 \\
\hline 4 & $\begin{array}{l}\text { Cempedak } \\
\text { (Artocarpus polyphema) }\end{array}$ & 0 & 9 & 0 & 40 & 0 & 16,3 & $\begin{array}{l}\text { B. dorsalis } \\
\text { B. umbrosa }\end{array}$ & $\begin{array}{c}5 \\
22\end{array}$ \\
\hline 5 & $\begin{array}{l}\text { Jambu air } \\
\text { (Syzygium aqueum) }\end{array}$ & 6 & 6 & 0 & 0 & 26 & 36,8 & B. dorsalis & 25 \\
\hline 6 & Jambu biji (Psydium guajava) & 3 & 17 & 14 & 0 & 22 & 28,6 & B. dorsalis & 21 \\
\hline 7 & Nangka (A. integra) & 19 & 9 & 4 & 0 & 20 & 19,2 & $\begin{array}{l}\text { B. dorsalis } \\
\text { B. umbrosa }\end{array}$ & $\begin{array}{c}3 \\
26\end{array}$ \\
\hline 8 & $\begin{array}{l}\text { Rampai (Solanum } \\
\text { lycopersicum) }\end{array}$ & 0 & 34 & 46 & 0 & 0 & 27,5 & B.cucurbitae & 18 \\
\hline & Jumlah jenis & 5 & 5 & 4 & 3 & 3 & & & \\
\hline
\end{tabular}

Keterangan : $\mathrm{SPL}=$ sistem penggunaan lahan, $\mathrm{KKP}=$ kebun kopi polikultur, $\mathrm{KKM}=$ kebun kopi monokultur, $\mathrm{LTP}=$ lahan tanaman pangan, $\mathrm{LTH}=$ lahan tanaman hortikultura, $\mathrm{PAA}=$ padang alang-alang 


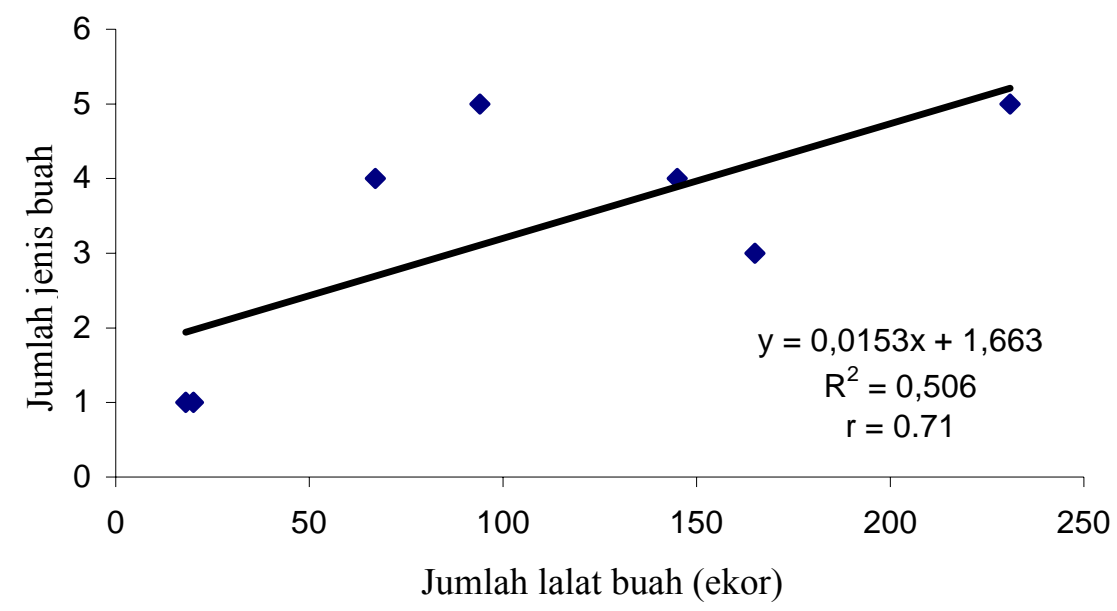

Gambar 1. Korelasi antara jumlah lalat buah dan jumlah jenis buah yang terdapat pada lahan

Tabel 4. Korelasi antara berat buah yang diinkubasi dan jumlah lalat buah yang muncul

\begin{tabular}{clcc}
\hline No. & \multicolumn{1}{c}{ Jenis buah } & $\mathrm{r}$ & $\mathrm{n}$ \\
\hline 1. & Belimbing (Averoa carambola) & $0,079^{\mathrm{tn}}$ & 9 \\
2. & Cabe merah (Capsicum annuum) & $-0,574^{\mathrm{tn}}$ & 10 \\
3. & Cabe rawit (C. frutescens) & $0,296^{\text {tn }}$ & 12 \\
4. & Cempedak (Artocarpus polyphema) & $0,923^{* *}$ & 8 \\
5. & Jambu air (Syzygium samarangense) & $0,624^{*}$ & 14 \\
6. & Jambu biji (Psydium guajava) & $0,454^{\text {tn }}$ & 8 \\
7. & Nangka (A. integra) & $0,364^{\text {tn }}$ & 11 \\
8. & Rampai (Solanum lycopersicum) & $-0,048^{\text {tn }}$ & 11 \\
\hline
\end{tabular}

Keterangan: ${ }^{\text {tn }}$ ) koefisien korelasi (r) tidak berbeda dengan nol pada taraf nyata 0,05 ;

*) koefisien korelasi berbeda dengan nol pada taraf nyata 0,05 ;

**) koefisien korelasi berbeda dengan nol pada taraf nyata 0,01

kelimpahan relatif mencapai $83,6 \%$. Sebaliknya, spesies B. (A.) furvus merupakan spesies yang kelimpahan relatifnya paling rendah $(0,2 \%)$. Lalat buah ini hanya ditemukan 1 ekor, yaitu pada SPL kebun kopi polikultur (KKP), terperangkap pada zat pemikat juice buah markisa (Tabel $1 \& 2$ ).

Keanekaragaman dan kelimpahan lalat buah bervariasi pada setiap sistem penggunaan lahan. Jumlah dan spesies lalat buah paling banyak (231 ekor, 4 spesies) ditemukan di lahan kebun kopi polikultur (KKP), dan paling sedikit ( 18-20 ekor, 1 spesies) di temukan di lahan hutan (HA dan HT). Sedangkan pada 4 lahan lain (KKM, LTP, LTH, dan PAA) jumlah lalat buah yang ditemukan bervariasi dari 67 ekor - 145 ekor, dengan $2-3$ spesies (Tabel 2). Adanya variasi jumlah dan species lalat buah yang ditemukan pada setiap penggunaan lahan disebabkan adanya perbedaan jumlah dan jenis buah sebagai pakan lalat buah pada setiap lahan. Semakin banyak jenis dan jumlah buah pada suatu lahan, semakin banyak pula jumlah dan jenis lalat buah yang ditemukan pada lahan tersebut (Tabel 2 \& 3, Gambar 1). Hal ini sesuai dengan laporan Kardinan (2007) bahwa keberadaan tanaman hortikultura, terutama buah-buahan sangat erat kaitannya dengan keberadaan dan kemelimpahan lalat buah.

Selama penelitian, jumlah dari setiap jenis lalat buah yang ditemukan bervariasi. B. dorsalis 
merupakan jenis lalat buah yang paling banyak ditemukan dibandingkan dengan jenis lalat buah yang lain. Hal ini berkaitan dengan ketersediaan tanaman inang $B$. dorsalis yang lebih banyak dibandingkan tanaman inang B. umbrosa atau B. cucurbitae pada habitat pengambilan sampel. Pada Tabel 3 dapat dilihat bahwa $B$. dorsalis memiliki tujuh jenis tanaman inang (No. 1 - 7), sedangkan B. umbrosa hanya mempunyai 2 jenis tanaman inang, yaitu cempedak (Artocarpus polyphema) dan nangka (A. integra), yang juga merupakan tanaman inang $B$. dorsalis. Inang untuk B. cucurbitae hanya 1 jenis, yaitu buah rampai (Salanum licopersicum). B. dorsalis dikenal dengan nama umum lalat buah oriental. Spesies ini merupakan hama penting yang banyak merusak buah dan sayuran di daerah Asia dan Asia Tenggara (Drew \& Hancock, 1994; Putra et al., 2006; Dinas Informasi dan Komunikasi, 2007; Hartanto, 2007; Kardinan, 2007; Vedder, 2007; Balittro, 2008). Lalat buah ini tersebar di Indonesia, India, Myanmar, Srilanka, Thailand, Filipina, Mikronesia, dan Hawai. Tumbuhan inangnya bervariasi, termasuk berbagai jenis buah-buahan dan sayuran. Lalat buah ini dilaporkan dapat merusak lebih dari 20 jenis buahbuahan, antara lain jeruk (Citrus spp.), pepaya (Carica papaya), cabe (Capsicum spp.), jambu air ( $S$. aqueum), jambu biji (P. guajava), belimbing (A. carambola), cengkeh (S. aromaticum), alpukat (Persea americana), nangka (A. integra), tomat ( $S$. lycopersicum), pisang (Musa paradisiaca) dan mangga (Mangifera indica) (Papulung \& Agus, 2006; Putra et al., 2006; Dinas Informasi dan Komunikasi, 2007; Hartanto, 2007; Kardinan, 2007; Vedder, 2007; Balittro, 2008). Di Jawa lalat buah ini merupakan hama penting pada tanaman cabe (Capsicum), baik cabe merah maupun cabe rawit. Di Bogor lalat buah ini selain menyerang cabe juga ditemukan menyerang belimbing (A. carambola), cengkeh (S. aromatica), mangga (M. indica, petai (Parkia speciosa), dan jeruk (Citrus spp.) (Siwi et al., 2006).

Analisis korelasi antara berat buah terinkubasi dan jumlah lalat buah yang muncul menunjukkan bahwa hanya buah cempedak dan jambu air yang beratnya mempunyai korelasi positif dengan jumlah lalat buah. Semakin berat buah cempedak atau jambu air yang diinkubasi semakin banyak lalat buah yang dihasilkan dari kedua jenis buah tersebut. Untuk enam jenis buah yang lain, berat buahnya tidak berkorelasi dengan jumlah lalat buah yang dihasilkan, walaupun tingkat persentase serangan di lahan pengamatan lebih tinggi (Tabel $3 \& 4$ ).

\section{SIMPULAN}

Di kawasan Bukit Rigis Sumberjaya, Lampung Barat ditemukan empat spesies lalat buah, yaitu Bactrocera (Bactrocera) dorsalis, B. (B.) umbrosa, B. (Zeugodacus) cucurbitae, dan B. (Afrodacus) furvus. Keanekaragaman dan kelimpahan lalat buah antarSPL di kawasan ini bervariasi bergantung pada jenis dan jumlah tanaman buah yang ditemukan di setiap SPL tersebut. B. dorsalis merupakan spesies lalat buah yang paling sering ditemukan, sedangkan spesies yang paling jarang ditemukan adalah $B$. furvus. Food lure dapat memerangkap lebih banyak spesies lalat buah sedangkan cue lure memerangkap lebih banyak jumlah lalat buah. Populasi lalat buah berkorelasi positif dengan berat buah cempedak dan jambu air.

\section{SANWACANA}

Publikasi ini merupakan bagian dari penelitian yang dibiayai oleh program global Conservation and Sustainable Management of Below-Ground Biodiversity (CSM-BGBD) yang dilaksanakan pada tujuh negara tropika (Brazil, Mexico, Cote d'Ivoire, Kenya, Uganda, India, dan Indonesia). Program ini dikoordinasikan oleh Tropical Soil Biology and Fertility Institute of CIAT (TSBF-CIAT) dengan dukungan dana dari Global Environment Facility (GEF) dan dukungan implementasi dari United Nations Environment Programme (UNEP) Perserikatan Bangsa-bangsa (PBB).

Penulis berterima kasih kepada Bapak Ir. I Gede Swibawa, M.S. (Fakultas Pertanian Universitas Lampung) yang telah membantu mempersiapakan alat perangkap dan pekerjaan di lapangan. Terima kasih juga disampaikan kepada Dhevi Widiastuti dan Angriani (Fakultas Matematika dan Ilmu Pengetahuan alam, Universitas Lampung) yang telah membantu koleksi data di lapangan dan identifikasi lalat buah di laboratorium. 


\section{DAFTAR PUSTAKA}

Agus, F., N. Gintings, \& M.V. Noordwijk. 2002 Konservasi Tanah untuk Areal Pertanian Berbasis Kopi di Sumberjaya, Lampung Barat. ICRAF. Bogor.

Asrida, E., F.X. Susilo \& L. Wibowo. 2001. Respons berbagai jenis lalat buah belimbing terhadap pembungkusan buah. J. Penel. Sains Tek. 7 (1): $76-86$.

Balittro. 2008. Perangkap Lalat Buah. http://www. pustaka deptan.go.id. Diakses 18 Maret 2008.

Dinas Kehutanan Lampung Barat. 1992. Rencana pelaksanaan pembangunan wilayah Kecamatan Sumberjaya dan sekitarnya dalam konteks lokal dan regional. Sumberjaya.

Dinas Informasi dan Komunikasi. 2007. Panen Mangga, Waspadai Lalat Buah. http://www. jatim.go.id. Diakses 20 Maret 2008.

Dowell, R.W. \& L.K. Wange. 1986. Process analysis and failure avoidance in fruit fly programs. Pest control: Operations and system analysis in fruit fly management. Ecological Sciences 11: 43 65.

Drew, R.A.I., G.H.S. Hooper, \& M.A. Bateman. 1982. Economic Fruit Flies of the South Pasific Region. $2^{\text {nd }}$ ed. Department of Primary Industry, Queensland. Brisbane.

Drew, R.A.I. \& D.L. Hancock. 1994. The Bactrocera dorsalis complex of fruit flies (Diptera: Tephritidae: Dacinae) in Asia. Bulletin of Entomological Research Suppl. (2).

Evizal, E., S. Budidarsono, \& F.E. Prasmatiwi. 2004. Land use history, land use intensity, and socioeconomic background of Lampung benchmark area, Sumberjaya Window, Indonesia. CSMBGBD Project Report, Bandar Lampung.

FAO. 1986. Report of the expert consultation on progress and problems in controlling fruit fly infestation. RAPA Publication 28: 1 - 18.
Hardy, D.E. 1977. Family Tephritidae. Pp. 44 - 134 In: A Catalog of the Diptera of the Oriental Region. Delfinado, M.D. \& Hardy, D.E. (eds.) Univ. Hawaii Press.

Hartanto, Y. 2007. Pengendalian Lalat Buah. http://www.tokopupuk.com/pengendalian lalat buah. Diakses 20 Maret 2008.

Kardinan, A. 2007. Tanaman Aromatik, Pengendali Hama Lalat Buah. http://www. dispertan jawatengah.go.id. Diakses 18 Maret 2008.

Orr, A. 2002. The importance of fruit fly taxonomy in Indonesia. Seminar Puslitbangtan (mimeo).

Papulung, A. \& N. Agus. 2006. Kajian Musuh Alami Lalat Buah Bactrocera dorsalis Hendel. Arsip penelitian Lembaga Penelitian Unhas http://www. unhas.ac.id/lemlit. Diakses 18 Maret 2008.

Pemcam Sumberjaya. 2004. Profil Kecamatan Sumberjaya Tahun 2003. Sumberjaya.

Putra, D.P., A. Hasyim \& Mardinus. 2006. Skrining tumbuhan atraktif terhadap lalat buah jantan Bactocera carambolae D\&H. Biota Jurnal Ilmiah Ilmu-ilmu Hayati. 11 (30):: 176-180.

Republika. 2008. Serangan Lalat Buah Merajalela, Petani Belimbing Terancam Gagal Panen. http://www. republika.co.id. Diakses 25 Maret 2008.

Siwi, S.S., P. Hidayat \& Suputa. 2006. Taksonomi dan Bioekologi Lalat Buah Penting di Indonesia (Diptera: Tephritidae). BB Biogen \& Dept. Agriculture, Fisheries \& Forestry Australia, Bogor.

Swibawa, I G., F.X. Susilo, I. Murti, \& E. Ristiyani. 2003. Serangan Dacus cucurbitae (Diptera: Trypetidae) pada buah mentimun dan pare yang dibungkus pada saat pentil. J. HPT Tropika 3 (2): $43-46$. 
Vedder, T. 2007. Serangan Lalat Buah Semakin Menggannas. http//www.bayi_online.com. Diakses 20 Maret 2008.
White, I.M. \& M.E. Marlene. 1992. Fruit flies of economic significance: Their identification and bionomics. CABI in association with ACIAR, Wallingford. 